5 - ORIGINAL ARTICLE

MATERIALS TESTING

\title{
In-vivo bone response to titanium screw implants anodized in sodium sulfate ${ }^{1}$
}

\author{
Flávio Alexandre Lima PinheiroI, Carlos Fernando de Almeida Barros Mourão, Vitor Senna Diniz ${ }^{\mathrm{II}}$, Paulo Cesar Silva ${ }^{\mathrm{III}}$, Luiz \\ Meirelles $^{\text {IV }}$, Emanuel Santos Juniorv, Alberto Schanaider ${ }^{\mathrm{VI}}$
}

DOI: http://dx.doi.org/10.1590/S0102-86502014000600005

IFellow Master degree, Postgraduate Program in Surgical Sciences, Department of Surgery, School of Medicine, Federal University of Rio de Janeiro (UFRJ), Rio de Janeiro-RJ, Brazil. Acquisition and interpretation of data, manuscript writing.

"Graduate student, School of Medicine, UFRJ. Scientific initiation student, Grant from Institutional Program for Scientific Initiation (PIBIC) of the National Council of Technological and Scientific Development (CNPq), Ministry of Science, Technology and Inovation), Brazil. Technical procedures, acquisition of data. IIIAssociate Professor, Postgraduate Program in Surgical Sciences, Department of Surgery, School of Medicine, UFRJ, Rio de Janeiro-RJ, Brazil. Acquisition and interpretation of data.

${ }^{\text {IV }} \mathrm{PhD}$, Assistant Professor, Department of Dentistry (SMD), School of Medicine and Dentistry, University of Rochester Medical Center, USA. Acquisition and interpretation of data.

${ }^{\mathrm{V}} \mathrm{PhD}$, Department of Metallurgical and Materials Engineering, UFRJ, Rio de Janeiro-RJ, Brazil. Acquisition and interpretation of data.

${ }^{\mathrm{VI}}$ Full Professor. Head, Experimental Surgical Center. Coordinator, Postgraduate Program in Surgical Sciences, Department of Surgery, School of Medicine, UFRJ, Rio de Janeiro-RJ, Brazil. Conception and design of the study, critical revision.

\section{ABSTRACT}

PURPOSE: To evaluate the early bone response to a nanotextured dental implant treated with sodium sulfate $\left(\mathrm{Na}_{2} \mathrm{SO}_{4}\right)$, using a rabbit model. METHODS: Twelve animals were randomly divided into group 1 (Control) - machined implants and group 2 (Test) - nanotextured implants. Extra-oral incision was performed to provide access to intended surgical site where the dental implant was inserted immediately after the extraction of the mandibular first premolar. Implant surface characterization was performed by scanning electron microscopy attached to energy dispersive spectroscopy and interferometry. Three weeks after surgery, the animals were induced to death and undecalcified sections of the samples were prepared for histological and histomorphometrical analysis.

RESULTS: Surface characterization of the implant demonstrated enhanced surface area of anodized group compared to Control group with $19.2 \% \pm 6.2$ versus $1.6 \pm 0.7$, respectively. Histological evaluation demonstrated new bone formation starting from the buccal and lingual cortical walls on both groups. After three weeks, significant higher bone contact of $27 \%(\mathrm{p}<0.05)$ was observed to nanotextured compared to machined implants (Control group).

CONCLUSION: The anodization with sodium sulfate nanostructures to the implant surface that resulted in faster osseointegration.

Key words: Dental Implants. Nanotechnology. Osseointegration. Rabbits. 


\section{Introduction}

After tooth extraction, changes in the alveolar bone and the healing process result in the formation of trabecular and medullary structures and significant bone loss is observed in the socket $^{1}$. The goal of implant rehabilitation therapy is to preserve soft and hard supporting tissues, preventing continuous bone loss.

Thus, in recent decades there has been a substantial development of synthetic prostheses to replace or restore the functionality of tissues in humans, and, in the context of dentistry, commercially pure titanium has become popular due to its biocompatibility and mechanical properties. Titanium is, therefore, the gold standard for the purpose of comparison between different materials ${ }^{2}$.

Modifications to the machined (also known as turned) implant design and electrochemical surface treatment (anodizing) of dental implants in the nanometer range (accurate to within 100 $\mathrm{nm}$, i.e., one millionth of a millimeter or less) enhance adhesion, differentiation, and cell proliferation that ultimately results in faster osseointegration ${ }^{3}$. Enhanced osseointegration will improve anchorage and will provide larger surface area for distribution of occlusal load. Indeed, the development of a different nanomodified implants showed the desirable ability to form apatite layers in vitro nanotexturization $^{4}$, as well as good response to the living bone ${ }^{5}$.

The investigation of healing events at the bone-implant interface would benefit from animal models with similar bone structure as found in human jaws. We have recently reported bone remodeling of rabbit sockets grafted with hydroxyapatite based a novel approach ${ }^{6}$ on the rabbit tooth extraction socket model ${ }^{7}$.

Since these $\mathrm{Ti}$ oxide films have presented promising results in laboratory tests, to study their performance in-vivo seems to be timely and useful.

\section{Methods}

The Ethics Committee for Animal Use of the Federal University of Rio de Janeiro (UFRJ) approved the in-vivo experimental procedures proposed (number 80/09), also carried out in accordance to the Care and Use of Laboratory Animals (National Institutes of Health) handbook rules.

Twelve adult male albino New Zealand rabbits (Orictolagus cuniculus) were housed under appropriated environmental conditions, exposed to 12 hours light-dark cycles with standard chow and water ad libitum. All animals were between 2.5 and $3.0 \mathrm{~kg}$ in weight. The experimental groups were randomly distributed (Control group - machined implants and Test group - nanotextured implants) and submitted to the same surgical procedure. The anesthesia was performed by intraperitoneal administration of ketamine ( $60 \mathrm{mg} / \mathrm{kg}$ weight $)$ and xylazine $(10 \mathrm{mg} / \mathrm{kg}$ weight $)$ in association with local anesthesia using lidocaine $1 \%$. Both superior maxilla and jaw were stabilized in open position and $5.0 \mathrm{~cm}$-long extra-oral longitudinal incisions was done from the last molar to the labial commissure encompassing the masseter. Thus, intrasulcular incisions were done in the molars, having $5.0 \mathrm{~mm}$ in length mesially to the first molar, with visibility of the posterior teeth, to facilitate subsequent extraction. After mucoperiosteal detachment, the first molar on the left mandible was extracted using forceps. The installation of implants with primary stability was performed immediately after extraction of the tooth, followed by simple layer suture (Figure 1). Postoperative analgesia was performed using oral tramadol hydrochloride and subcutaneously with antibiotic enrofloxacin $0.1 \mathrm{ml} / \mathrm{kg}, 5 \%$ (single dose). At the end of a postoperative period of three weeks, the animals were painlessly euthanized with an anesthetic overdose of sodium pentothal for extraction of a $3 \mathrm{~cm}$ mandibular segment enclosing the implant.

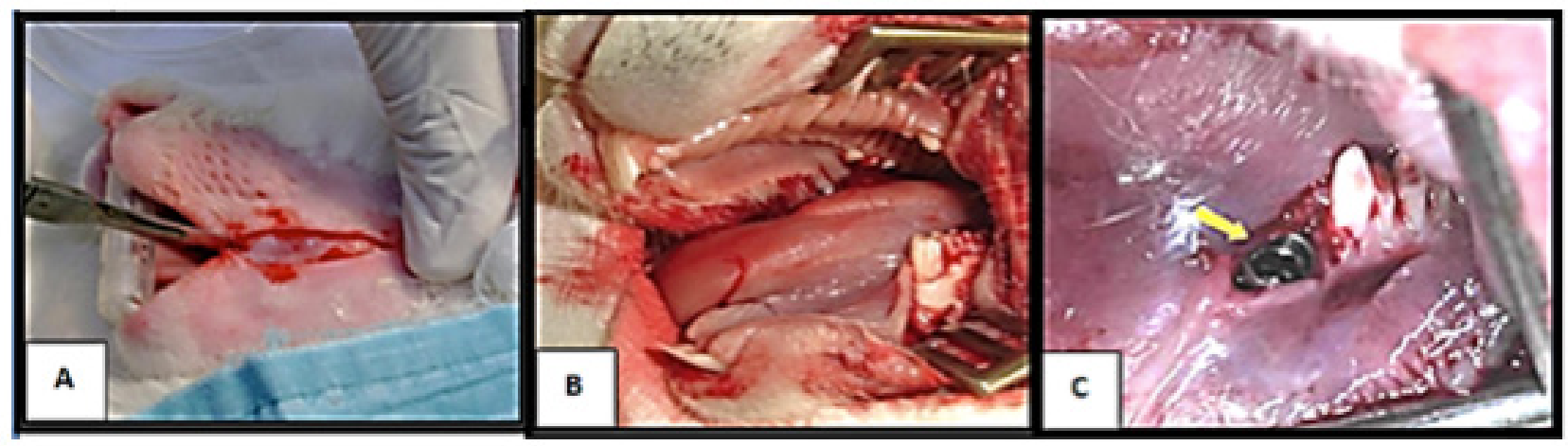

FIGURE 1 - Experimental surgery steps for screw implant insertion in rabbits' molar tooth: (A) incision to access the tooth; (B) exposing the tooth; (C) implant already inserted after molar extraction. 


\section{Surface treatment and characterization}

Machined or turned commercially pure-titanium implants (INP Biomedical, Sao Paulo, Brazil) with dimensions of 4.0 × 8.0 $\mathrm{mm}^{2}$ were submitted to surface modification by anodic oxidation (AO) process. Prior to AO treatment, the as-received samples were degreased in acetone ultrasonic bath for $15 \mathrm{~min}$ and dried in air. A circular Pt mesh (2.0 mm diameter) was employed as cathode where the Ti screws implants (anode) were gently centered inside. Then, the AO process was carried out at potentiostatic mode in $1.0 \mathrm{MNa}_{2} \mathrm{SO}_{4}$ electrolyte under of $100 \mathrm{~V}$ anodic voltage for $1 \mathrm{~min}$.

Surface morphologies were observed by scanning electron microscopy (SEM, JEOL $6460 \mathrm{LV}$ ) working at $20 \mathrm{kV}$ with an energy dispersive spectrometer (EDS) coupled to. Roughness analysis was performed by profilometry using an interferometer apparatus (NewView 7300, Zygo Corporation, USA) and scanning $200 \mu \mathrm{m} x$ $260 \mu \mathrm{m}$ areas with $0.4 \mu \mathrm{m}$ and $0.05 \mathrm{~nm}$ lateral and vertical resolutions, respectively. Raw data were treated by using Gaussian filters, which is suitable for separating the shape and waviness of the measured roughness. Mean average height $(\mathrm{Sa})$, developed surface area (Sdr) and local summits per area (Sds) were the main parameters measured.

\section{Histological and histomorphometry evaluation}

Extracted samples were fixed in $10 \%$ formalin solution at pH 7 for 10 days. Thus, the samples were placed in polyethylene vessels containing pure resin (LR White Hard Grade, UK), dehydrated in increasing alcohol solutions from $70 \%$ to $100 \%$ concentrations and replaced every $48 \mathrm{~h}$. The specimens were kept in vacuum, stirred and stored at $4{ }^{\circ} \mathrm{C}$ for nine days. After that, they were embedded in polytetrafluoroethylene (Teflon) molds and maintained at $60^{\circ} \mathrm{C}$ for resin polymerization. The polymerized pieces were halved and polished using an Exakt system (Norderstedt, Germany). They were cut in the buccal to lingual direction using a diamond saw tool.
Surfaces containing implants were abraded using sandpapers until surfaces were smoothes. Then, the pieces were glued on an acrylic plate and their exposed surfaces were abraded and polished again to obtain $70 \mu \mathrm{m}$ thicknesses, approximately. Finally, samples used for histological study were stained with both Stevenel's blue e Alizarin red markers and examined by optical microscopy (Eclipse 80i, Nikon, Japan) with x1 - x20 magnifications. Histomorphometry evaluations were carried out by image analysis using commercial software (Nikon Elements BR, Nikon, Japan).

\section{Statistical analysis}

Bone-implant contact results were statistically analyzed by the Wilcoxon method (Signed Rank Test), where $p$-value $<0.05$ refers to significant difference.

\section{Results}

\section{Surface characterization}

SEM-EDS evaluation of machine implants (Control group) showed irregular surfaces with presence of micron-sized grooves and the chemical elements were titanium (Ti) and oxygen (O) (Figure 2A). Anodized implants revealed quite uneven porous surfaces embedded on a complex matrix with a wide range of pores size distribution. The qualitative EDS analysis also shows that the nanotextured implant surface was consisted of Ti, O, and the presence of traces of residual sodium $(\mathrm{Na})$ and sulfur $(\mathrm{S})$ derived from the electrolyte used in the anodization process (Figure 2B). 

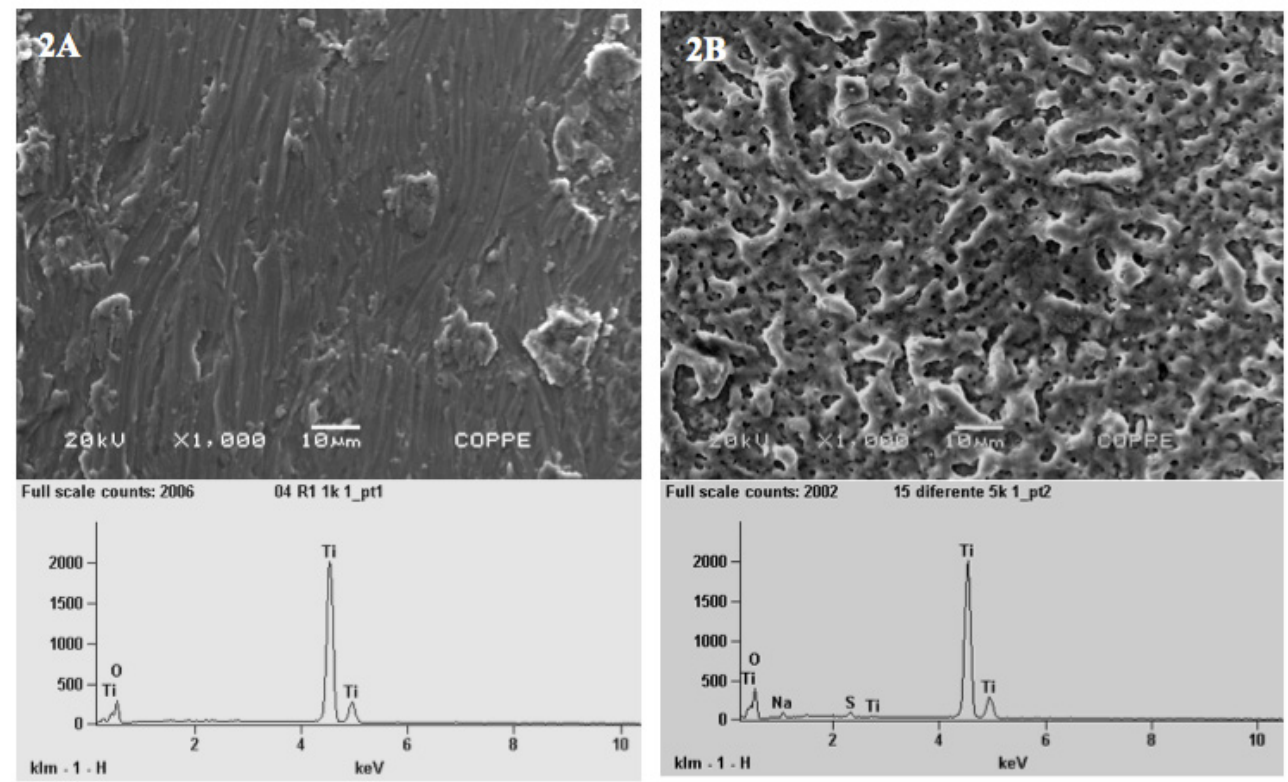

FIGURE 2 - SEM micrographies (x1.000) and EDS spectra of the machined or turned implants (2A) and treated Ti screw or anodized implants (2B). The surface of the Control group (2A) was irregular with micron-size grooves with presence of Ti and O (Graphic attached to Figure 2A). The Test group (2B) showed micro pores and nanopores and the nanotexturized implant surface was consisted of Ti, $\mathrm{O}$ and a small quantities of residual sodium (Na) and sulfur (S) (Graphic attached to Figure 2B).

3D analysis of the surfaces images of the machined implants by interferometer revealed the presence of a more flattened surface, but with grooves and micro-fissures. The surface images of the nanotextured implant had a porous appearance with diffuse roughness (Figure 3). Data obtained from both groups were used for roughness parameters determination.
No difference was detected for both average height deviation (Sa) and density of summits (Sds) parameters. However, surface area (Sdr) of nanotextured implants was significantly larger than that of the turned implants $(\mathrm{p}<0.01)$.

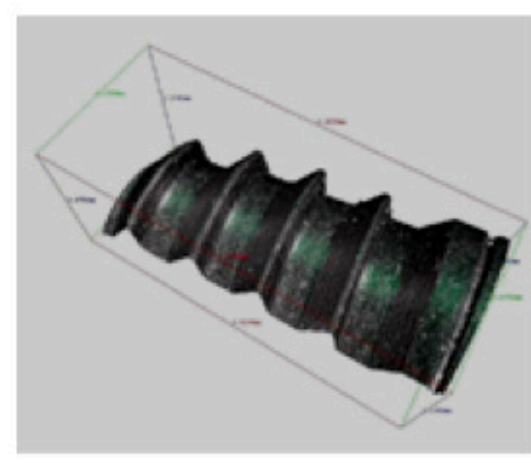

A

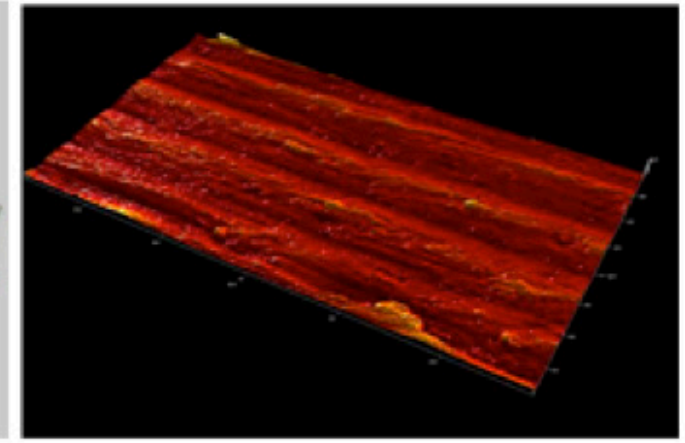

B

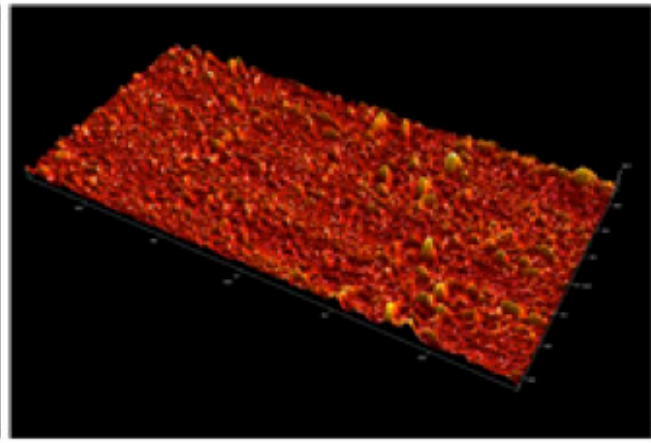

C

FIGURE 3 - 3D surface images obtained by profilometry: (A) 3D image of machined screw implant; (B) machined screw implant surface; and (C) anodized screw implant surface. Data obtained from B and C were used for roughness parameters determination. 


\section{Histology and histomorphometry}

All implants were stable and partially covered by a soft tissue. Osseointegration was observed in all implants placed, with the presence of active osteoblasts and osteocytes in new bone matrix. Dental implant placed inside the rabbit socket presented new bone formation on the buccal and lingual walls of the socket. Moreover, such bone formation was found on the apex of the implant, inside the gap limited by the bottom of the defect and the implant. At higher magnification, closer apposition of newly formed bone was observed on the nanotextured samples (Test group) in contrast to the machined one (Control) (Figure 4).

a
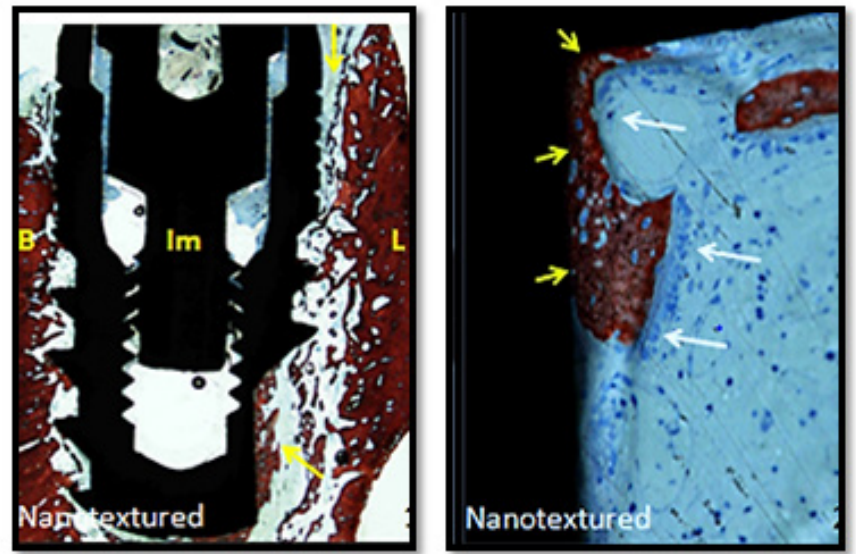

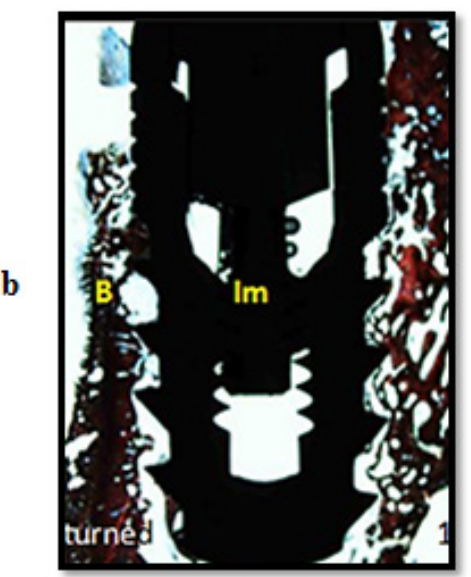

$\mathbf{X} 1$

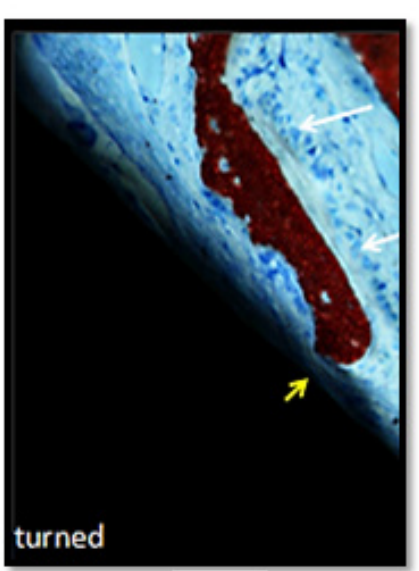

$\mathbf{X} 20$
FIGURE 4 - Optical images of the histological evaluation of the healing process around the (a) machined/Control and (b) turned/treated implants. $\mathrm{B}$ - buccal wall; L -lingual wall, Im - Implant (x1 magnification). Yellow arrows indicate the contact area between the implants surface and newly formed bone tissue. Osteoblasts activities (stained in blue, white arrows) and bone-implant contact (short yellow arrows) were observed at higher magnification (x20).

Histomorphometry analysis of the bone contact showed an enhanced bone formation when nanotextured samples (19.4 $\pm 7.2 \%)$ were compared to turned $(14.2 \pm 5.9 \%)$ implants $(\mathrm{p}=0.46)$ (Figure 5).

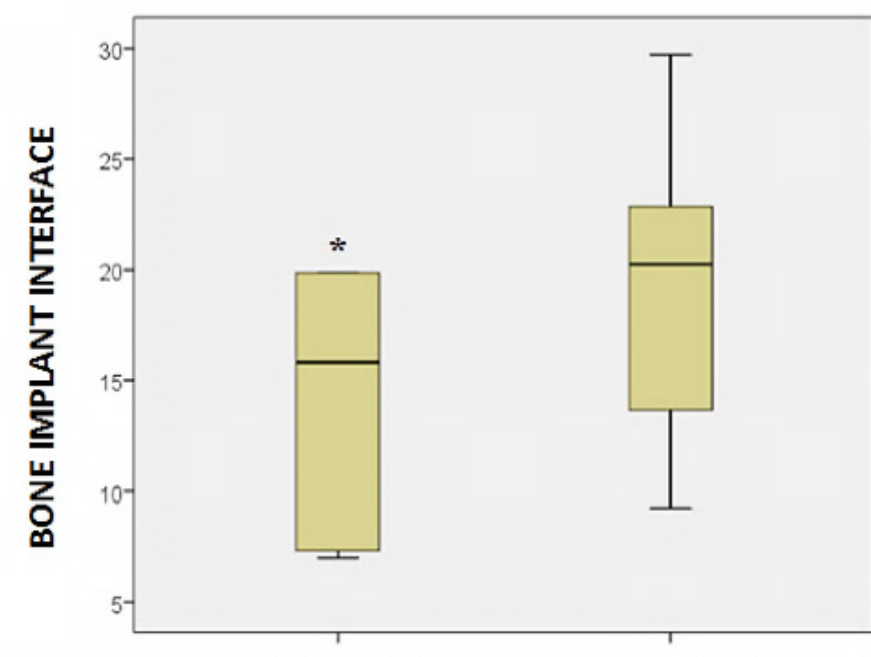

Machined

Nanotexturized

FIGURE 5 - Bone implant interface was lager in nanotexturized (Test group) than in machined (Control group) implants $\left({ }^{*} \mathrm{p}<0.05\right)$.

\section{Discussion}

For this study, we used the rabbit taking into account the anatomical features of the mandibular structure, the compatibility of the model with studies of implants and also the applicability to human beings ${ }^{9}$.

A recent systematic review about in-vivo tests found that the insertion of dental implants with intra-oral access is mainly limited to animals as large as dogs, monkeys, sheeps and pigs ${ }^{10}$. Additionally, in-vivo studies using rabbits, are usually carried out in tibia or femur ${ }^{11,12}$. However, such usual models impose several restrictions on translational studies, since these bones have different origins compared to the jaw (first arch) and possess a lower cortical-medullary thickness, thereby interfering with adequate bone-implant $\operatorname{contact}^{13}$. For a more realistic surgical applicability, the in-vivo model must include the tooth alveolus as an anatomical cavity. Indeed, as previously demonstrated by the authors ${ }^{6}$, the rabbit implant socket is a feasible and successful in vivo model for the investigation of bone remodeling on fresh extraction sockets in smaller animals.

An essential step for mechanical stabilization of the implants in human beings is the sign of bone remodeling, which must have already appeared between the 8 th and 12 th weeks after implantation ${ }^{14}$. In our study, socket healing with formation of bone matrix was observed at the end of the third week. These results were similar to those obtained by Kurita et al. ${ }^{15}$ and allowed for more rapid investigation of implant osseointegration. When the tooth alveolus anatomy is taken into account and a good surgical 
technique used, dental implants promptly inserted after tooth extraction have shown excellent clinical success for the long-term use in both animals and human beings ${ }^{16}$. So this approach was followed in our experimental model.

For the surface analysis and topographic characterization of titanium implants in both groups, it was used the parameters of SEM and interferometer devices, suggested by Wennerberg et $a l .{ }^{17}$, whose properties complement each other. The advantage of SEM with EDS is its excellent depth of focus, which allowed high-definition imaging of the rough surfaces and established the chemical elements or contaminants present in the samples ${ }^{18}$. However a quantitative and 3D analysis of the topography was only achieved by interferometry ${ }^{19}$. The measurement of surface roughness parameters, based on a $3 \mathrm{D}$ analysis, showed a significant increase of the hybrid Sdr parameter to the nanotextured implant $(19.19 \%)$ compared to machined one (1.55\%), which means a large area at the surface treated with anodization.

Several studies into the application of dental implants have been developing continuously, with recent emphasis on nanotechnology ${ }^{20}$. This is a promising area for the generation of new prosthetic devices with bioactive surfaces, eventually with so-called smart surfaces, responsive to the local environment of implantation and promoting tissue regeneration ${ }^{21}$.

The turned dental implant that contains minimal grooves on the surface is used as a standard when comparing surface treatments. Titanium anodic coatings prepared in $1.0 \mathrm{M} \mathrm{Na}_{2} \mathrm{SO}_{4}$ $(100 \mathrm{~V})$ have a rutile-rich crystalline structure, presenting rough surface with interconnected micro and nanopores ${ }^{22}$. So, the anodizing is an electrochemical process used to coat a metallic surface with nanoparticles and can turn the Ti surfaces of the implants into osteoconductive materials. In this way, the activity of mesenchymal cells and osteoblasts are facilitated during the bone remodeling. The osteoblast cells are attached on the surface by interposition of a tissue that interweaves into surface irregularities of the implant by biochemical and mechanical adhesion processes ${ }^{23,24}$

The surface treatment of cp-Ti screw implants with sodium sulfate $\left(\mathrm{Na}_{2} \mathrm{SO}_{4}\right)$, as proposed in this study, led to forming Ti oxide coatings $(1.6 \mu \mathrm{m}$ thick) with a rough and micron-sized porous layer on its surface with interconnected pores. The presented roughness can play an important role on exposing a larger surface to the biological medium, while the pores are able to anchor the osteoblast cell lamellipodium, as previously observed by Santos et al. ${ }^{4}$. Besides the better osteoblasts adherence on the $\mathrm{TiO}_{2}$ coatings with $\mathrm{Na}_{2} \mathrm{SO}_{4}$ electrolyte, such surface also improves osteoblast proliferation ${ }^{4}$.
Studies of patients treated with anodized implants in the mandible and maxilla revealed, respectively, a greater contact with the adjacent bone tissue than that observed in implants with turned surfaces, after mean healing periods of $61 / 2$ months and 3 $1 / 2$ months $^{25}$. In nanotextured implants (test group), the presence of a larger area of bone-implant contact and changes in the chemical properties of the implants due to the incorporation of sodium and sulfate ions upon anodizing seem to be able to stimulate osseointegration.

A few number of studies concerned about $\mathrm{Ti}$ anodic oxidation in $\mathrm{Na}_{2} \mathrm{SO}_{4}$ solutions have been published ${ }^{8}$ but reports of $\mathrm{Na}_{2} \mathrm{SO}_{4}$ type of anodizing for dental implants in vivo were not found in the scientific literature in this context.

\section{Conclusion}

The in-vivo experimental model by using titanium implants in molar socket of rabbits provided evidence that nanotexturization of the surface of the dental implants, anodized with sodium sulfate, promoted earlier osseointegration with an improved bone response than turned implants commercially available.

\section{References}

1. Cardaropoli G, Araujo M, Lindhe J. Dynamic of bone tissue formation in tooth extraction sites. An experimental study in dogs. J Clin Periodontol. 2011 Sep;30(9):809-18. PubMed PMID: 12956657.

2. Albrektsson T. A multicenter report on osseointegrated oral implants. J Prosthet Dent; 1988 Jul;60(1):75-8. PubMed PMID: 3042986.

3. Meirelles L, Currie F, Jacobsson M, Albrektsson T, Wennerberg A. The effect of chemical and nanotopographical modifications on the early stages of osseointegration. Int J Oral Maxillofac Implants. 2008 Jul-Aug;23(4):641-7. PubMed PMID: 18807559.

4. Santos Jr E, Kuromoto NK, Campos DM, Mazzaro I, Soares GDA. In vitro behavior of two distinct titanium surfaces obtained by anodic oxidation. Key Eng Mat. 2008;20(3):669-72.

5. Sul YT, Johansson CB, Röser K, Albrektsson T. Qualitative and quantitative observations of bone tissue reactions to anodized implants. Biomaterials. 2002 Apr;23(8):1809-17. PubMed PMID: 11950051.

6. Manso JEF, Mourão CFABM, Pinheiro FA, Ferreira ML, Silva PC, Schanaider A. Molars extraction for bone graft study in rabbits. Acta Cir Bras. 2011;26 Suppl 2:66-9. PubMed PMID: 22030817.

7. Kuboki Y, Hashimoto F, Ishibashi K. Time-dependent changes of collagen crosslinks in the socket after tooth extraction in rabbits. J Dent Res. 1988 Jun;67(6):944-8. PubMed PMID: 3170907.

8. Cui X, Kim H-M, Kawashita M, Wang L, Xiong T, Kokubo T, Nakamura T. Preparation of bioactive titania films on titanium metal via anodic oxidation. Dent Mater. 2009 Jan;25(1):80-6. doi: 10.1016/j.dental.2008.04.012. Epub 2008 Jul 2

9. Schanaider A, Silva PC. Uso de animais em cirurgia experimental. Acta Cir Bras. 2004;19(4):441-7. 
10. Vignoletti F, Abrahamsson I. Quality of reporting of experimental research in implant dentistry. Critical aspects in design, outcome assessment and model validation. J Clin Periodontol. 2012 Feb; 39 Suppl 12:6-27. doi: 10.1111/j.1600-051X.2011.01830.x.

11. Cordioli G, Majzoub Z, Piattelli A, Scarano A. Removal torque and histomorphometric investigation of 4 different titanium surfaces: an experimental study in the rabbit tibia. Int J Oral Maxillofac Implants. 2000 Sep-Oct;15(5):668-74. PubMed PMID: 11055134.

12. Giavaresi G, Ambrosio L, Battiston GA, Casellato U, Gerbasi R, Finia M. Histomorphometric, ultrastructural and microhardness evaluation of the osseointegration of a nanostructured titanium oxide coating by metal-organic chemical vapour deposition: an in vivo study. Biomaterials. 2004 Nov;25(25):5583-91. PubMed PMID: 15159074.

13. Wei H, Zili L, Yuanlu C, Biao Y, Cheng L, Xiaoxia W, Yang L, Xing W. Effect of icariin on bone formation during distraction osteogenesis in the rabbit mandible. Int J Oral Maxillofac Surg. 2011 Apr;40(4):413-8. doi: 10.1016/j.ijom.2010.10.015.

14. Berglundh T, Abrahamsson I, Lang NP, Lindhe J. De novo alveolar bone formation adjacent to endosseous implants. A model study in the dog. Clin Oral Implant Res. 2003 Jun;14(3):251-62. PubMed PMID: 12755774.

15. Kurita Y, Hashimoto T, Takei T, Kawai T, Hayakawa T. Changes in collagen types during the healing of rabbit tooth extraction wounds. J Dent Res. 1985 Jan;64(1):28-32. PubMed PMID: 3855416.

16. Rosenquist B, Grenthe B. Immediate placement of implants into extraction sockets: Implant Survival. Int J Oral Maxillofac Implants. 1996 Mar-Apr;11(2):205-9. PubMed PMID: 8666452.

17. Wennerberg A, Albrektsson T. Suggested guidelines for the topographic evaluation of implant surfaces. Int J Oral Maxilofac Implants. 2000 May-Jun;15(3):331-4. PubMed PMID: 10874798.

18. Gaggl A, Schultes G, Müller WD, Kärcher H. Scanning electron microscopical analysis of laser-treated titanium implant surfaces - a comparative study. Biomaterials. 2000 May;21(10):1067-73. PubMed PMID: 10768759.

19. Wieland M, Textor M, Spencer ND, Brunette DM. Wavelengthdependent roughness: a quantitative approach to characterizing the topography of rough titanium surfaces. Int J Oral Maxillofac Implants. 2001 Mar-Apr;16(2):163-81. PubMed PMID: 11324205.

20. Variola F, Brunski JB, Orsini G, Oliveira PT, Wazen R, Nanci A Nanoscale surface modifications of medically relevant metals: stateof-the art and perspectives. Nanoscale. 2011 Feb;3(2):335-53. doi: $10.1039 / \mathrm{c} 0 \mathrm{nr} 00485 \mathrm{e}$.

21. Tomsia AP, Launey ME, Lee JS, Mankani MH, Wegst UG, Saiz E. Nanotechnology approaches to improve dental implants. Int J Oral Maxillofac Implants. 2011;Suppl 26:25-44. PubMed PMID: 21464998.
22. Wennerberg A, Albrektsson T. On implant surfaces: a review of current knowledge and opinions. Int J Oral Maxillofac Implants. 2010 Jan-Feb;25(1):63-74. PubMed PMID: 20209188.

23. Lavenus S, Louarn G, Layrolle P. Nanotechnology and dental implants. Int JBiomater. 2010;28(6):91-7. doi: 10.1155/2010/915327.

24. Sykaras N, Iacopino AM, Marker VA, Triplett RG, Woody RD. Implant materials, design and surface topographies: their effect on osseointegation. A literature review. Int J Oral Maxillofac Implants. 2000 Sep-Oct;15(6):675-90. PubMed PMID: 11055135.

25. Ivanoff CJ, Widmark G, Johansson C, Wennerberg A. Histologic evaluation of bone response to oxidized and turned titanium microimplants in human jawbone. Int J Oral Maxillofac Implants. 2003

May-Jun;18(3):341-8. PubMed PMID: 12814308.

\section{Acknowledgement}

To INP Biomedical for providing us with machined Ti implants.

\section{Correspondence:}

Carlos Fernando de Almeida Barros Mourão

Universidade Federal do Rio de Janeiro

Avenida Professor Rodolpho Paulo Rocco, 225

21941-913 Rio de Janeiro - RJ Brasil

mouraoufrj@yahoo.com.br

Tel.: (55 21)2562-2220 Ramal 2220

Received: Jan 15, 2014

Review: March 14, 2014

Accepted: April 16, 2014

Conflict of interest: none

Financial sources: National Council for Scientific and Technological Development $(\mathrm{CNPq})$ and Rio de Janeiro Research Foundation (FAPERJ)

1 Research performed at Experimental Surgical Center, Department of Surgery, School of Medicine, Federal University of Rio de Janeiro (UFRJ), Brazil. Part of Master degree thesis, Postgraduate Program in Surgical Sciences, UFRJ. Tutor: Alberto Schanaider. 